\title{
Use of gabapentin for perioperative pain control - A meta-analysis
}

\author{
Philip WH Peng MBBS FRCPC ${ }^{1}$, Duminda N Wijeysundera MD FRCPC ${ }^{2}$, Carina CF Li MBBS FANZCA ${ }^{1}$
}

\begin{abstract}
PWH Peng, DN Wijeysundera, CCF Li. Use of gabapentin for perioperative pain control - A meta-analysis. Pain Res Manage 2007;12(2):85-92.
\end{abstract}

BACKGROUND: Gabapentin, an anticonvulsant, has recently been suggested as an effective postoperative 'analgesic' agent. The objective of the present study was to examine the analgesic effectiveness, opioid-sparing effects and side effects associated with the use of gabapentin in a perioperative setting.

METHODS: Following the Quality of Reporting of Meta-analyses recommendations, nine electronic databases until February 2006 were searched, without language restriction, for randomized controlled trials comparing gabapentin with control for postoperative pain control. Outcome measures, namely, $24 \mathrm{~h}$ cumulative opioid consumption, visual analogue scale pain scores and adverse effects, were expressed as odds ratios, ratio of means or weighted mean differences (as appropriate), which were aggregated under the fixed or random effects models.

RESULTS: Gabapentin caused a 35\% reduction in total opioid consumption over the first $24 \mathrm{~h}$ following surgery (ratio of means 0.65 , $95 \%$ CI 0.59 to 0.72 ), a significant reduction in postoperative pain at rest (in the first $24 \mathrm{~h}$ ) and with movement (at $2 \mathrm{~h}, 4 \mathrm{~h}$ and $12 \mathrm{~h}$ ), regardless of whether treatment effects were expressed as ratios of means or weighted mean differences, and a reduction of vomiting (relative risk [RR] 0.73, 95\% CI 0.56 to 0.95 ) and pruritus (RR 0.30, $95 \% \mathrm{CI} 0.13$ to 0.70 ). It was associated with a significant increase in dizziness (RR 1.40, 95\% CI 1.06 to 1.84 ) and an increase in sedation of borderline significance (RR 1.65, 95\% CI 1.00 to 2.74).

CONCLUSION: Gabapentin improves the analgesic efficacy of opioids both at rest and with movement, reduces analgesic consumption and opioid-related adverse effects, but is associated with an increased incidence of sedation and dizziness.

Key Words: Analgesic; Gabapentin; Meta-analysis; Opioids; Postoperative pain; Surgery

$\mathrm{D}$ espite the use of new drugs and delivery modalities, studies have shown that acute postoperative pain continues to be undermanaged $(1,2)$. Approximately three of four patients experience acute pain after surgery, and $80 \%$ of these have moderate to extreme pain. Opioid analgesics are the cornerstone of pharmacological postoperative pain management (3), although they also contribute to increased morbidity and associated hospital costs $(4,5)$. A balanced, multimodal approach of providing postoperative analgesia has been suggested to improve analgesia and minimize opioid-related adverse events (6). Various agents or techniques have been well investigated (7), including acetaminophen (8), nonsteroidal anti-inflammatory

\section{L'utilisation de la gabapentine pour le soulage- ment de la douleur périopératoire : méta- analyse}

CONTEXTE : La gabapentine, un anticonvulsivant, se montrerait également un analgésique postopératoire efficace, d'après des observations récentes. La présente étude avait pour but d'examiner l'efficacité analgésique du médicament, son effet d'épargne d'opioïdes et ses effets indésirables en phase périopératoire.

MÉTHODE : À la suite des recommandations sur la qualité des rapports de méta-analyses, une recherche a été entreprise dans neuf bases de données électroniques et poursuivie jusqu'en février 2006, sans restriction de langue, sur des essais réalisés avec hasardisation, comparant la gabapentine à des traitements témoins pour le soulagement de la douleur périopératoire. Les mesures de résultats, soit la consommation cumulée d'opiö̈des sur $24 \mathrm{~h}$, les cotations de la douleur sur une échelle visuelle analogue et les effets indésirables, ont été exprimées sous forme de risque relatif approché, de rapports de moyennes ou d'écarts de moyennes pondérées, selon le cas, puis intégrées globalement dans les modèles à effets fixes ou à effets aléatoires.

RÉSULTATS : La gabapentine a permis une réduction de $35 \%$ de la consommation totale d'opiö̈des au cours des 24 premières heures postopératoires (rapport des moyennes : 0,65; intervalle de confiance [IC] à $95 \%: 0,59$ - 0,72), une diminution significative de la douleur postopératoire au repos, au cours des 24 premières heures, et au moment de l'exécution des mouvements, au bout de $2 \mathrm{~h}$, de $4 \mathrm{~h}$ et de $12 \mathrm{~h}$, peu importe que les effets du traitement aient été exprimés sous forme de rapports de moyennes ou d'écarts de moyennes pondérées, ainsi qu'une diminution des vomissements (risque relatif [RR] : 0,73; IC à 95 \% : 0,56$0,95$ ) et du prurit (RR : 0,30; IC à $95 \%: 0,13-0,70)$. Par contre, le médicament a été associé à une augmentation significative des étourdissements (RR : 1,40; IC à $95 \%: 1,06$ - 1,84) et à une augmentation significativement limite de la sédation (RR : 1,65; IC à $95 \%: 1,00-2,74$ ). CONCLUSION : La gabapentine augmente l'efficacité analgésique des opioïdes, tant au repos qu'à l'exécution des mouvements, diminue la consommation d'analgésiques et les effets indésirables liés aux opioïdes, mais elle est associée à une augmentation de l'incidence de la sédation et des étourdissements.

Department of Anesthesiology and Pain Management, ${ }^{1}$ Toronto Western and ${ }^{2}$ General Division, University Health Network, University of

Toronto, Toronto, Ontario

Correspondence: Dr Philip WH Peng, McL 2-405, Toronto Western Hospital, 399 Bathurst Street, Toronto, Ontario M5T 2 S8.

Telephone 416-603-5118, fax 416-603-6494, e-mail philip.peng@uhn.on.ca 
Thus, these studies may not have the power to detect differences in side effects. Similarly, these studies may not have the power to detect possible increased rates of side effects of gabapentin, such as dizziness, which may impact on postoperative recovery.

The objective of the present study was to examine the analgesic effectiveness, opioid-sparing effects and side effects associated with the perioperative use of gabapentin.

\section{METHODS}

The present meta-analysis adhered to the recommendations of the Quality of Reporting of Meta-analyses recommendations (15).

\section{Inclusion and exclusion criteria}

Eligible studies were parallel-group, randomized, controlled trials enrolling adults (18 years or older) undergoing surgery under general anesthesia, regional anesthesia and monitored anesthesia care. The interventions assessed were the preoperative (within $24 \mathrm{~h}$ ), intraoperative or postoperative (within $24 \mathrm{~h}$ ) administration of gabapentin. Trials had to report any of the following outcomes: cumulative analgesic consumption (24 h), visual analogue scale (VAS) pain scores or adverse effects (dizziness, sedation, respiratory depression, nausea, vomiting, pruritus or urinary retention). Studies incorporating a local anesthetic technique or nerve block as part of the anesthetic regimen were excluded.

\section{Search strategy}

Eligible trials were identified using MEDLINE (1966 to February 2006), EMBASE (1980 to February 2006), PubMed (last searched February 2006), the Cochrane Clinical Trials Register (1st Quarter 2006), Science Citation Index, Controlled Trials Register, TEXTMED, Science Direct, IngentaConnect and Google Scholar. The search used the following subject headings and text terms: "gabapentin", "Neurontin", "postoperative care", "postoperative period", "perioperative care”, "surgery", "pain treatment", "analgesic" and "analgesia" (16). Bibliographies of included articles and published reviews were also searched. No language restrictions were applied. Unpublished trials were not sought, but authors of included studies were contacted to provide additional data. Studies that were reported only as abstracts or letters were excluded.

\section{Methods of review}

All three authors (PP, DW, CL) independently performed literature searches and assessed all identified full papers for inclusion. Reasons for exclusion were documented for all excluded studies. The following data were abstracted by two authors (DW, CL) onto data abstraction forms: patient demographic data, surgery, treatments, follow-up, 24 h cumulative analgesic consumption, time to first analgesic, VAS pain scores (rest and movement at $2 \mathrm{~h}, 4 \mathrm{~h}, 12 \mathrm{~h}$ and $24 \mathrm{~h}$ after surgery), dizziness, sedation, respiratory depression, nausea, vomiting, pruritus and urinary retention. Outcome definitions used by the original researchers were accepted. When the data on pain and adverse effects were incomplete, or when the pain score was presented as a median rather than mean $\pm \mathrm{SD}$, the first authors of those articles were contacted for further information. Three reviewers also independently rated study quality on the basis of the adequacy of randomization (method reported), allocation concealment, double-blinding and follow-up. All discrepancies were resolved by consensus.

\section{Statistical analyses}

Analyses were performed using Review Manager 4.2.8 (Cochrane Collaboration, Denmark). Initially, heterogeneity was measured using the $\mathrm{I}^{2}$ statistic. This value is the proportion of total variation that is explained by between-study variation as opposed to chance $(17,18)$. Higher $\mathrm{I}^{2}$ statistics imply more heterogeneity among pooled studies than would be expected by chance alone. In cases of low heterogeneity $\left(\mathrm{I}^{2}=0 \%\right)$, data were pooled under the fixed effects model; otherwise, the random effects model was used (19). Statistical significance was defined by a two-tailed $\mathrm{P} \leq 0.05$.

Binary outcomes were expressed as pooled relative risks (RR) with 95\% CIs. The RR was chosen to aggregate binary data because of its easy interpretability and stability (in contrast to risk difference and number needed to treat) with varying baseline risks (20). Pooled effects on time to first analgesic were expressed as weighted mean differences. The pooling of data on $24 \mathrm{~h}$ cumulative analgesic use was complicated by the differing postoperative analgesic regimens in the included studies. Aggregating data as weighted mean differences entailed standardizing all analgesic doses (ie, conversion to 'morphine-equivalents'), which was not possible given that a wide variety of analgesic agents was used and that some of them, such as tramadol, had no reliable equivalent ratio. Treatment effects on cumulative 24 h opioid use were therefore expressed as the more clinically meaningful 'ratio of means'; namely, the ratio of mean analgesic use in the gabapentin versus control arms. The methods of Friedrich et al (21) were used to calculate the pooled ratios of means. Treatment effects on mean VAS pain scores at rest and movement were calculated as both ratio of means and weighted mean differences at four prespecified time points after surgery: $2 \mathrm{~h}, 4 \mathrm{~h}, 12 \mathrm{~h}$ and $24 \mathrm{~h}$.

\section{Sensitivity analyses}

Sensitivity analyses were planned a priori to determine whether the choice of included studies influenced pooled treatment effects. The first sensitivity analysis assessed the relationship between study quality and treatment effects. The meta-analyses were repeated in high-quality studies, which were defined as studies fulfilling all of the four criteria: adequate randomization with method reported, proper allocation concealment, double-blinding and accounting for dropouts. The second sensitivity analysis involved using funnel plots to assess for publication bias (22). The final sensitivity analysis assessed the relationship between severity of postoperative pain and treatment effects. Previous studies have suggested that VAS pain scores must exceed $30 \mathrm{~mm}$ for a study to detect analgesic effects (23). The meta-analyses were therefore repeated in studies that reported mean VAS pain scores at rest above $30 \mathrm{~mm}$ in the control arm at any of the prespecified time points ( $2 \mathrm{~h}, 4 \mathrm{~h}, 12 \mathrm{~h}$ or $24 \mathrm{~h})$.

\section{RESULTS}

The search results are presented in Figure 1. One study was excluded after complete evaluation because the treatment arm assessed the effects of gabapentin in combination with other treatments (24). Eighteen studies (25-42), encompassing 1181 patients, were included for analysis (Table 1). Most studies were of good quality, with the exception being adequacy of allocation concealment (Table 2). Participants' mean ages ranged from 29 to 52 years of age. Women comprised 32\% to $100 \%$ of participants.

The most common dose of gabapentin assessed was $1200 \mathrm{mg}$ daily (12 studies), with some studies using doses as low as $300 \mathrm{mg}$ daily (Table 1$)$. Eleven studies (25,28-33,36,38-40) 
administered gabapentin as a single dose within $1 \mathrm{~h}$ to $2 \mathrm{~h}$ before surgery; the remainder involved initiating therapy on the day before surgery or continuing it for up to 10 days after surgery (Table 1). With the exception of Rorarius et al (29), all studies used an inactive placebo (Table 1 ). The study that used an active control was excluded from analyses pertaining to sedation and respiratory depression.

\section{Analgesic consumption}

Fourteen studies (25-28,31-40), encompassing 1027 participants, reported effects on cumulative $24 \mathrm{~h}$ analgesic consumption. Gabapentin resulted in a $35 \%$ reduction in total analgesic consumption over the first $24 \mathrm{~h}$ following surgery (ratio of means $0.65,95 \%$ CI 0.59 to 0.72 ; P<0.001), albeit with significant heterogeneity $\left(\mathrm{I}^{2}=84.4 \%\right)$. Subgroup analyses based on surgical procedure, gabapentin dose or study quality did not explain this heterogeneity. The data on time to first analgesic was available in three studies $(29,30,38)$ (171 patients). It was delayed $7.9 \mathrm{~min}$ by gabapentin $(95 \% \mathrm{CI}$ 4.2 to $11.6 ; \mathrm{P}<0.001)$, with minimal heterogeneity $\left(\mathrm{I}^{2}=0 \%\right)$.

\section{Pain scores}

Gabapentin caused a significant reduction in postoperative pain at rest $(25-28,30-42)$ in the first $24 \mathrm{~h}$, by $27 \%$ to $39 \%$ ( $7.2 \mathrm{~mm}$ to $14.3 \mathrm{~mm}$ on a scale of $0 \mathrm{~mm}$ to $100 \mathrm{~mm}$ ), regardless of whether treatment effects were expressed as ratios of means or weighted mean differences (Figure 2). Similarly, aside from $24 \mathrm{~h}$ after surgery, gabapentin significantly reduced pain with movement $(25-27,31,34,35,37,38)$ by $18 \%$ to $28 \%$ (VAS $8.2 \mathrm{~mm}$ to $10.2 \mathrm{~mm}$ ) after surgery (Figure 3 ). The pooled effects on VAS pain scores displayed significant heterogeneity, which was not explained by subgroup analyses based on surgical procedure, gabapentin dose or study quality (Figures 2 and 3).

\section{Adverse effects}

Gabapentin was associated with a significant increase in dizziness (RR 1.40, 95\% CI 1.06 to 1.84 ), with minimal heterogeneity (Table 3 ). It was also associated with an increase in sedation of borderline significance (RR 1.65 , 95\% CI 1.00 to 2.74), albeit with significant heterogeneity $\left(\mathrm{I}^{2}=83.3 \%\right)$. With regard to the opioid-sparing effects, gabapentin significantly reduced vomiting and pruritus (Table 3 ). The heterogeneity observed in analyses pertaining to sedation and nausea was not explained by subgroup analyses based on surgical procedure, gabapentin dose or study quality.

\section{Sensitivity analyses}

Aside from pain with movement at $12 \mathrm{~h}$ and $24 \mathrm{~h}$ after surgery, the results were not affected by study quality or severity of postoperative pain (Table 4). Funnel plots revealed no obvious publication bias with regard to opioid consumption, pain scores or adverse effects.

\section{DISCUSSION}

Gabapentin was introduced initially by Pfizer Inc in the early 1990s as an anticonvulsant, but is better known as an effective treatment for neuropathic pain (43). It is not considered an analgesic per se. A study published in 2002 (25) prompted investigators to rethink that gabapentin may be a broad-spectrum analgesic (44). Since then, 19 studies have been published. In the present meta-analysis, we have shown that gabapentin

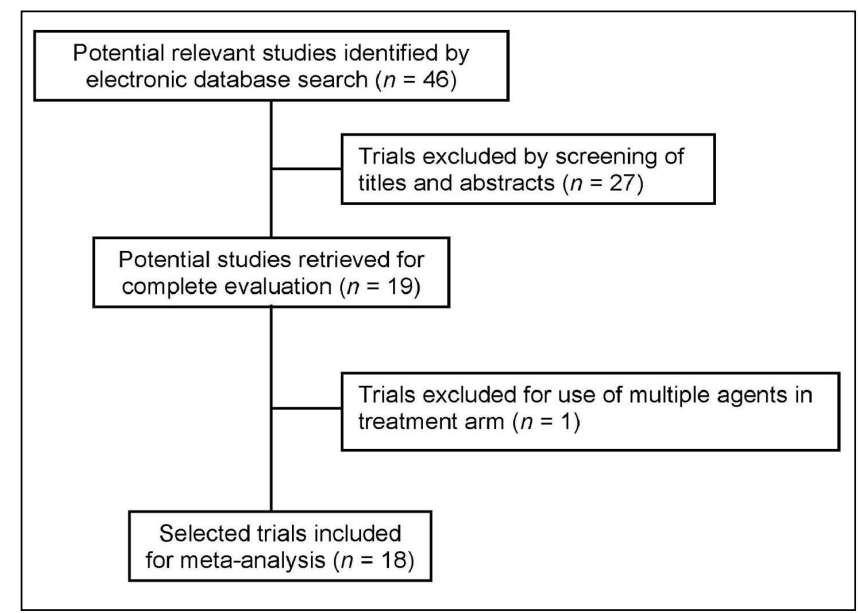

Figure 1) Meta-analysis flow diagram

reduces pain scores, both at rest and with movement following various surgeries, lengthens the time for analgesic rescue, decreases the consumption of opioids and, most importantly, lowers rates of opioid-related side effects. The pain score at rest was reduced by $27 \%$ to $39 \%$ (VAS $7.2 \mathrm{~mm}$ to $14.3 \mathrm{~mm}$ on a scale of $0 \mathrm{~mm}$ to $100 \mathrm{~mm}$ ) during the first $24 \mathrm{~h}$, and the pain score with movement was reduced by $18 \%$ to $28 \%$ (VAS $8.2 \mathrm{~mm}$ to $10.2 \mathrm{~mm}$ ) in the first $12 \mathrm{~h}$.

At the time of publication, three meta-analyses on this topic have been published (45-47). However, we have performed the most extensive search, and the number of studies included in this meta-analysis was 18 , compared with eight (45), 12 (46) and 16 (47) studies in the other meta-analysis. Furthermore, we were able to contact all except two authors for further information. Ho et al (47) excluded the data on pain score in four studies because the pain score was presented as a median or was not presented. However, we were able to get those data directly from the authors. As a result, we had the most extensive data collection for analysis of side effects, pain scores at rest and pain scores associated with movement. The latter were not presented in any of those three metaanalyses.

Our findings led to the question of how gabapentin works in reducing postoperative pain. In the past few decades, there has been a substantial improvement in the understanding of the mechanism of surgical pain (48-50). The neural pathway is no longer viewed as a 'hard-wire system' - it demonstrates neural plasticity, the neurobiological means by which changes in the nervous system can modulate responses to any stimulus. Following surgery, the intense influx of pain signal from tissue trauma can amplify and modify pain through a process called sensitization (central and peripheral sensitization). Of particular interest is central sensitization, in which the excitability and responsiveness of dorsal horn neurons to pain transmission is enhanced (50). The results of these changes contribute to abnormal pain responses such as pain sensation to innocuous stimuli (allodynia), enhanced pain responses (hyperalgesia) and spread of hypersensitivity beyond injured tissue. Because some of these modulation processes may turn into modification such as enhancement of gene expression, the pain may persist beyond apparent tissue healing, contributing to chronic postsurgical pain syndromes $(51,52)$. 
TABLE 1

Characteristics of the studies included in the present meta-analysis

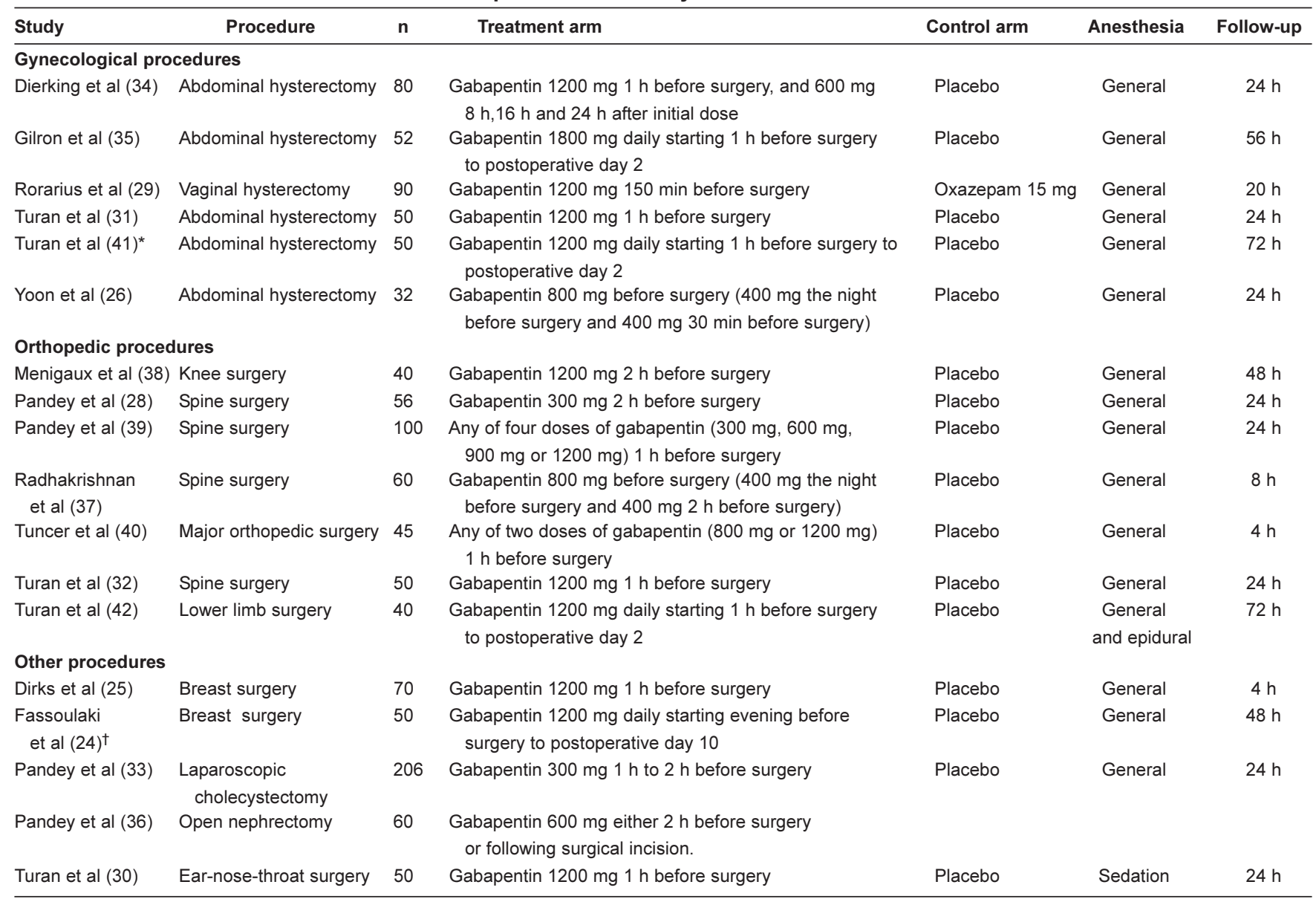

${ }^{*}$ Additional two arms that assessed celecoxib (alone and in conjunction with gabapentin) were excluded; ${ }^{\dagger}$ Additional arm that assessed mexilitene was excluded

TABLE 2

Quality of studies included in the present meta-analysis

\begin{tabular}{|c|c|c|c|c|c|c|}
\hline Study & Procedure & $\begin{array}{c}\text { Randomization } \\
\text { method described }\end{array}$ & $\begin{array}{c}\text { Allocation } \\
\text { concealment }\end{array}$ & Double-blinded & $\begin{array}{l}\text { Drop-outs } \\
\text { accounted }\end{array}$ & $\begin{array}{l}\text { Jadad } \\
\text { score* }^{*}\end{array}$ \\
\hline \multicolumn{7}{|c|}{ Gynecological procedures } \\
\hline Dierking et al (34) & Abdominal hysterectomy & + & + & + & + & 5 \\
\hline Gilron et al (35) & Abdominal hysterectomy & + & + & + & + & 5 \\
\hline Rorarius et al (29) & Vaginal hysterectomy & + & - & + & + & 5 \\
\hline Turan et al (31) & Abdominal hysterectomy & + & + & + & + & 5 \\
\hline Turan et al $(41)^{*}$ & Abdominal hysterectomy & + & + & + & + & 5 \\
\hline Yoon et al (26) & Abdominal hysterectomy & - & - & + & + & 4 \\
\hline \multicolumn{7}{|l|}{ Orthopedic procedures } \\
\hline Menigaux et al (38) & Knee surgery & + & - & + & + & 5 \\
\hline Pandey et al (28) & Spine surgery & + & - & - & - & 2 \\
\hline Pandey et al (39) & Spine surgery & + & - & + & + & 5 \\
\hline Radhakrishnan et al (37) & Spine surgery & + & + & + & - & 4 \\
\hline Tuncer et al (40) & Major orthopedic surgery & - & - & - & - & 1 \\
\hline Turan et al (32) & Spine surgery & + & + & + & + & 5 \\
\hline Turan et al (42) & Lower limb surgery & + & + & + & + & 5 \\
\hline \multicolumn{7}{|l|}{ Other procedures } \\
\hline Dirks et al (25) & Breast surgery & + & + & + & + & 5 \\
\hline Fassoulaki et al $(24)^{\dagger}$ & Breast surgery & + & + & + & + & 5 \\
\hline Pandey et al (33) & Laparoscopic cholecystectomy & + & - & + & - & 4 \\
\hline Pandey et al (36) & Open nephrectomy & + & - & + & + & 5 \\
\hline Turan et al (30) & Ear-nose-throat surgery & + & + & + & + & 5 \\
\hline \multicolumn{2}{|c|}{ Proportion meeting quality criteria, \% } & 89 & 56 & 89 & 78 & \\
\hline
\end{tabular}

*See reference 68 for details. + Information present; - Information absent 


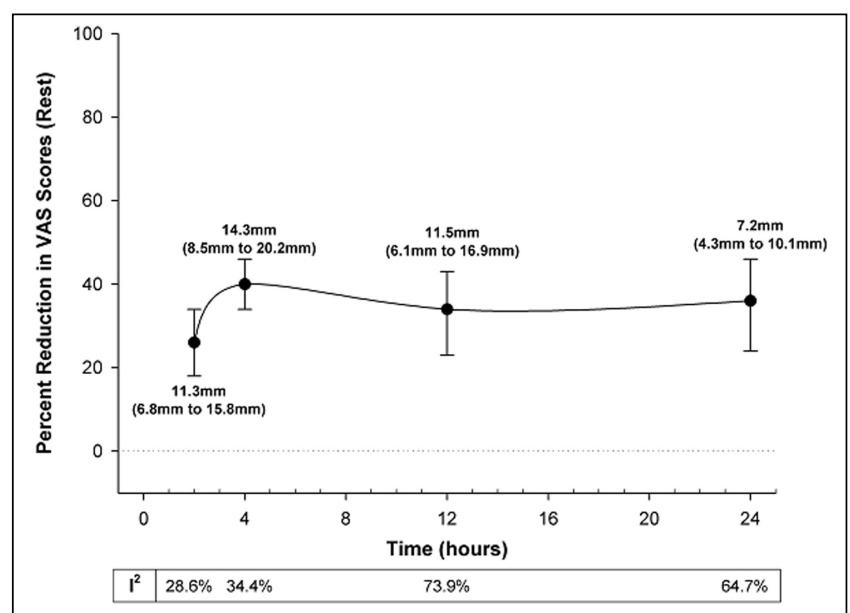

Figure 2) Per cent reduction in visual analogue scale (VAS) pain scores at rest with gabapentin over the first $24 \mathrm{~h}$ following surgery. The closed circles are the point estimates for pooled treatment effects, expressed as ratios of means (random effects model) at $2 \mathrm{~h}, 4 \mathrm{~h}, 12 \mathrm{~h}$ and $24 \mathrm{~h}$ following surgery. The error bars are the corresponding $95 \%$ CIs. The table below the graph reports the heterogeneity ( $I^{2}$ statistic) for these treatment effects. The text adjacent to each point estimate is the same treatment effect expressed as the absolute reduction in VAS scores (weighted mean difference in random effects model) with 95\% CI

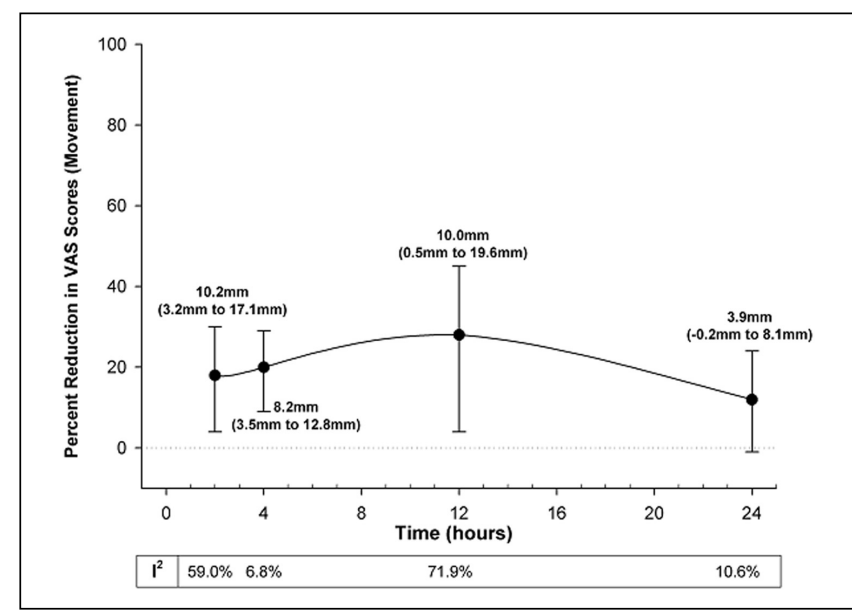

Figure 3) Per cent reduction in visual analogue scale (VAS) pain scores with movement by gabapentin over the first $24 \mathrm{~h}$ following surgery. The closed circles are the point estimates for pooled treatment effects, expressed as ratios of means (random effects model) at $2 \mathrm{~h}, 4 \mathrm{~h}, 12 \mathrm{~h}$ and $24 \mathrm{~h}$ following surgery. The error bars are the corresponding 95\% CIs. The table below the graph reports the heterogeneity (I $I^{2}$ statistic) for these treatment effects. The text adjacent to each point estimate is the same treatment effect expressed as the absolute reduction in VAS scores (weighted mean difference in random effects model) with $95 \% \mathrm{CI}$

TABLE 3

Adverse effects associated with perioperative gabapentin use

\begin{tabular}{|c|c|c|c|c|c|}
\hline Outcome & $\begin{array}{l}\text { Number of studies } \\
\text { (number of patients) }\end{array}$ & Relative risk & $95 \% \mathrm{Cl}$ & $\mathbf{P}$ & $\mathbf{I}^{2}$ \\
\hline Sedation* & $12(905)$ & 1.65 & 1.00 to 2.74 & 0.05 & $83.3 \%$ \\
\hline Nausea & $17(1196)$ & 0.91 & 0.68 to 1.20 & 0.50 & $46.7 \%$ \\
\hline Vomiting & $14(803)$ & 0.73 & 0.56 to 0.95 & 0.02 & $0 \%$ \\
\hline
\end{tabular}

*One study (29) that used an active control (oxazepam $15 \mathrm{mg}$ ) was excluded from this analysis

TABLE 4

Sensitivity analyses based on study quality and severity of postoperative pain - the second sensitivity analysis involved repeating analyses in studies that reported a mean control arm visual analogue scale (VAS) pain score at rest $\leq 30$ mm at any prespecified time point

\begin{tabular}{|c|c|c|c|c|c|c|}
\hline \multirow[b]{2}{*}{$\begin{array}{l}\text { Duration after } \\
\text { surgery (h) }\end{array}$} & \multicolumn{5}{|c|}{ Ratio of means (95\% CI) } & \multirow[b]{2}{*}{$\mathbf{I}^{2}$} \\
\hline & $\begin{array}{l}\text { Primary } \\
\text { analysis }\end{array}$ & $\mathbf{I}^{2}$ & High-quality studies & $I^{2}$ & $\begin{array}{c}\text { Control arm VAS } \\
\text { score } \geq 30 \mathrm{~mm}\end{array}$ & \\
\hline \multicolumn{7}{|l|}{ Pain at rest } \\
\hline 2 & $0.74(0.66$ to 0.82$)$ & $28.60 \%$ & 0.67 (0.56 to 0.79$)$ & $39.60 \%$ & $0.72(0.64$ to 0.81$)$ & $31.30 \%$ \\
\hline 4 & $0.60(0.54$ to 0.66$)$ & $34.40 \%$ & $0.58(0.47$ to 0.70$)$ & $29.00 \%$ & $0.58(0.53$ to 0.64$)$ & $30.60 \%$ \\
\hline 12 & $0.66(0.57$ to 0.77$)$ & $73.90 \%$ & $0.52(0.31$ to 0.86$)$ & $80.80 \%$ & 0.65 (0.56 to 0.77$)$ & $76.10 \%$ \\
\hline 24 & $0.64(0.54$ to 0.76$)$ & $64.70 \%$ & $0.59(0.47$ to 0.75$)$ & $21.30 \%$ & $0.64(0.53$ to 0.77$)$ & $67.40 \%$ \\
\hline \multicolumn{7}{|c|}{ Pain with movement } \\
\hline 2 & $0.82(0.70$ to 0.96$)$ & $59.0 \%$ & 0.75 (0.58 to 0.98$)$ & $69.1 \%$ & $0.78(0.64$ to 0.95$)$ & $59.3 \%$ \\
\hline 4 & $0.80(0.71$ to 0.91$)$ & $6.8 \%$ & 0.75 (0.64 to 0.88$)$ & $0.0 \%$ & 0.75 (0.65 to 0.86$)$ & $0.0 \%$ \\
\hline 12 & $0.72(0.55$ to 0.96$)$ & $71.9 \%$ & 0.64 (0.39 to 1.07$)$ & $76.5 \%$ & $0.66(0.49$ to 0.88$)$ & $63.0 \%$ \\
\hline 24 & $0.88(0.76$ to 1.01$)$ & $10.6 \%$ & $0.92(0.77$ to 1.10$)$ & $17.7 \%$ & $0.87(0.74$ to 1.04$)$ & $28.1 \%$ \\
\hline \multicolumn{7}{|l|}{ Total opioid use } \\
\hline 24 & $0.65(0.59$ to 0.72$)$ & $84.4 \%$ & 0.64 (0.52 to 0.79$)$ & $87.7 \%$ & $0.66(0.60$ to 0.72$)$ & $80.1 \%$ \\
\hline
\end{tabular}


Despite extensive investigations, the mechanism of how gabapentin works is still unknown. Although it is an analogue of gamma-aminobutyric acid (GABA), it is neither active at $\mathrm{GABA}_{\mathrm{A}}$ or $\mathrm{GABA}_{\mathrm{B}}$ receptors nor metabolically converted to GABA $(53,54)$. Its known main site of action is the alpha $a_{2}$-delta subunit of presynaptic voltage-gated calcium channels (55). However, other targets, such as sodium channels, N-methyl-Daspartic acid receptors, monoaminergic and opioid pathways, have been implicated $(53,54)$. Gabapentin does not affect the calcium ion influx of normal neurons. It reduces calcium ion influx at presynaptic terminals in hyperexcited neurons (51), which may lead to reduction of release of excitatory neurotransmitters such as glutamate, substance P and noradrenaline. Thus, gabapentin appears to reduce the hyperexcitability of dorsal horn neurons that is induced by tissue damage.

In the acute pain setting, a meaningful improvement in pain score has been investigated. In patients with moderate baseline pain, the minimal improvement, as seen on the VAS, is $13 \mathrm{~mm}$ on a scale from $0 \mathrm{~mm}$ to $100 \mathrm{~mm}$, or a $20 \%$ reduction from baseline (56). Although the improvements in pain scores in the present analysis were modest $(7.2 \mathrm{~mm}$ to $14.3 \mathrm{~mm}$ at rest during the first $24 \mathrm{~h}$, and $8.2 \mathrm{~mm}$ to $10.2 \mathrm{~mm}$ in the first $12 \mathrm{~h}$ with movement), these reductions represented more than $20 \%$ reduction from the baseline pain score at rest. The improvement in analgesia is far better than those achieved with ketamine (11) and is comparable with cyclooxygenase 2 inhibitors (41).

Despite the benefits of gabapentin, one has to be cautious about its side effects. The two most common side effects of gabapentin in the management of chronic pain are somnolence and dizziness (43). In this meta-analysis, gabapentin also increased the rates of dizziness and sedation in surgical patients. Similar to most acute pain studies, the quality of reporting of side effects was generally poor (57). For instance, most included gabapentin studies did not describe the methods for reporting the occurrence and severity of side effects. For studies that reported dizziness, only three assessed its severity $(25,29,34)$. Most of the reported dizziness episodes were mild $(25,29)$ and did not affect patient satisfaction (42). Furthermore, the most common dose regimen was a single dose of $1200 \mathrm{mg}$ before surgery $(25,28-32,34,38,42)$, which is a very high initial dose compared with the recommended dose for the management of chronic neuropathic pain (58). In the chronic pain setting, the starting dose usually does not exceed $300 \mathrm{mg}$ daily to avoid dizziness and sedation. The dose is then gradually titrated upward to the desired therapeutic dose. However, adjusting the dose in the preoperative period is impractical, and thus, a higher dose is chosen. Interestingly, a dose-response study suggested no benefit of a starting dose above $600 \mathrm{mg}$ (39). Further studies are required to elucidate the optimal dose and severity of side effects. Despite this, physicians should be cautious about the potential for sedation and dizziness, especially in ambulatory surgical patients.

\section{Limitations}

There are several limitations in this meta-analysis, mostly related to the methodological weakness of the original studies. Although we used the more conservative random effects model to aggregate data from the gabapentin randomized, controlled trials, the underlying heterogeneity among the included trials limited the strength of our overall conclusions. This called for the need of a properly designed, randomized, controlled trial. The results of the present meta-analysis provide valuable data for improving the design of future trials. We are not able to comment on the dose-response for efficacy because of the diverse regimen used. Before surgery, 15 studies prescribed a single dose (300 mg to $1200 \mathrm{mg}$ ) and three studies prescribed repeated doses. Following surgery, only four studies prescribed repeated doses, varying from $1200 \mathrm{mg}$ once daily for two days to $400 \mathrm{mg}$ three times a day for 10 days. Only two studies $(26,39)$ examined the analgesic effects of gabapentin in more than one dose group. The other limitation is related to the reporting of side effects. Most studies mainly focused on analgesic effectiveness and did not systemically evaluate adverse effects. Reporting of the methods of assessment, severity of adverse effects and patient withdrawal related to the side effects is recommended in analgesic trials (59).

\section{Suggestion for further studies}

Further studies should improve the reporting of side effects and their severity (57). When evaluating the efficacy of a drug, the frequency, severity and the impact (distress) of different adverse effects should be considered. A composite scoring system, the Opioid-related Symptoms Distress Scale, has been suggested for reporting the opioid-related side effects (59).

So far, there is insufficient information to recommend a specific dose regimen for gabapentin. Only one study examined dose-response efficacy and suggested that the highest efficacy was a single preoperative dose of $600 \mathrm{mg}$ (39). However, analgesic effects can be procedure specific $(60,61)$, and more studies are needed to contribute to a dose recommendation.

Gabapentin has been shown to reduce mechanical hyperalgesia in several preclinical pain models (62-64). However, studies showing that it reduces hyperalgesia in postoperative patients are lacking. Further studies are recommended to examine the effects of gabapentin on mechanical hyperalgesia on and around the wound. This will give valuable information of how gabapentin works in the acute pain setting.

There are other advantages of using gabapentin in the postoperative setting. It has been used to relieve anxiety and improve sleep quality, both of which are important to patient care in the perioperative period $(65,66)$. However, only one study examined the effect of gabapentin on relieving anxiety. Further studies are recommended to explore these clinical advantages of gabapentin with well-validated measurement tools.

Finally, antisensitization medications such as ketamine have been demonstrated to reduce the prevalence of chronic postsurgical pain (67). More studies are encouraged to examine the effects of gabapentin on the prevalence and severity of chronic postsurgical pain in different surgical models.

\section{CONCLUSION}

Gabapentin may be a new class of analgesic medication that targets the sensitization process. In our meta-analysis, we were able to show that gabapentin improves the analgesic efficacy of the opioids both at rest and with movement, and reduces opioid consumption and opioid-related adverse effects. However, it also increases rates of dizziness and sedation. Further studies are required to study the impact of these side effects, the optimum analgesic dose and the other nonanalgesic effects of gabapentin, such as anxiolysis and sleep improvement.

ACKNOWLEDGEMENTS: DN Wijeysundera is supported in part by the Canadian Institutes of Health Research (Ottawa, Ontario). 


\section{REFERENCES}

1. Apfelbaum JL, Chen C, Mehta S, Gan TJ. Postoperative pain experience: Results from a national survey suggest postoperative pain continues to be undermanaged. Anesth Analg 2003;97:534-40.

2. Warfield CA, Kahn CH. Acute pain management: Programs in U.S. hospitals and experiences and attitudes among U.S. adults. Anesthesiology 1995;83:1090-4.

3. Austrup ML, Korean G. Analgesic agents for the postoperative period. Opioids. Surg Clin North Am 1999;79:253-73.

4. Wheeler M, Oderda GM, Ashburn MA, Lipman AG. Adverse events associated with postoperative opioid analgesia: A systemic review. J Pain 2002;3:159-80.

5. Oderda GM, Evans S, Lloyd J, et al. Cost of opioid-related adverse drug events in surgical patients. J Pain Symptom Manage 2003;25:276-83

6. Kehlet H, Dahl JB. The value of 'multimodal' or 'balanced analgesia' in postoperative pain treatment. Anesth Analg 1993; 77:1048-56.

7. White PF. The changing role of non-opioid analgesic techniques in the management of postoperative pain. Anesth Analg 2005;101:S5-22.

8. Rømsing J, Møiniche S, Dahl JB. Rectal and parenteral paracetamol, and paracetamol in combination with NSAIDs, for postoperative analgesia. Br J Anaesth 2002;88:215-26.

9. Marret E, Kurdi O, Zufferey P, Bonnet F. Effects of nonsteroidal anti-inflammatory drugs on patient-controlled analgesia morphine side effects: Meta-analysis of randomized controlled trials. Anesthesiology 2005;102:1249-60.

10. Romsing J, Moiniche S. A systematic review of COX-2 inhibitors compared with traditional NSAIDs, or different COX-2 inhibitors for post-operative pain. Acta Anaesthesiol Scand 2004;48:525-46.

11. Elia N, Tramer MR. Ketamine and postoperative pain A quantitative systematic review of randomised trials. Pain 2005;113:61-70.

12. Borgeat A, Ekatodramis G, Schenker CA. Postoperative nausea and vomiting in regional anesthesia. Anesthesiology 2003;98:530-47.

13. Dahl JB, Mathiesen O, Moiniche S. 'Protective premedication': An option with gabapentin and related drugs? A review of gabapentin and pregabalin in in the treatment of post-operative pain. Acta Anaesthesiol Scand 2004;48:1130-6.

14. Kehlet H. Postoperative opioid sparing to hasten recovery. What are the issues? Anesthesiology 2005;102:1083-5.

15. Moher D, Cook DJ, Eastwood S, Olkin I, Rennie D, Stroup DF. Improving the quality of reports of meta-analyses of randomised controlled trials: The QUOROM statement. Quality of Reporting of Meta-analyses. Lancet 1999;354:1896-900.

16. Dickersin K, Scherer R, Lefebvre C. Identifying relevant studies for systematic reviews. BMJ 1994;309:1286-91.

17. Higgins JP, Thompson SG. Quantifying heterogeneity in a metaanalysis. Stat Med 2002;21:1539-58.

18. Higgins JP, Thompson SG, Deeks JJ, Altman DG. Measuring inconsistency in meta-analyses. BMJ 2003;327:557-60.

19. DerSimonian R, Laird N. Meta-analysis in clinical trials. Control Clin Trials 1986;7:177-88.

20. Furukawa TA, Guyatt GH, Griffith LE. Can we individualize the 'number needed to treat'? An empirical study of summary effect measures in meta-analyses. Int J Epidemiol 2002;31:72-6.

21. Friedrich JO, Adhikari N, Herridge MS, Beyene J. Meta-analysis: Low-dose dopamine increases urine output but does not prevent renal dysfunction or death. Ann Intern Med 2005;142:510-24.

22. Egger M, Davey SG, Schneider M, Minder C. Bias in meta-analysis detected by a simple, graphical test. BMJ 1997;315:629-34.

23. Kalso E, Smith L, McQuay HJ, Andrew MR. No pain, no gain: Clinical excellence and scientific rigour - Lessons learned from IA morphine. Pain 2002;98:269-75.

24. Fassoulaki A, Triga A, Melemeni A, Sarantopoulos C. Multimodal analgesia with gabapentin and local anesthetics prevents acute and chronic pain after breast surgery for cancer. Anesth Analg 2005;101:1427-32.

25. Dirks J, Fredensborg BB, Christensen D, Fomsgaard JS, Flyger H, Dahl JB. A randomized study of the effects of single-dose gabapentin versus placebo on postoperative pain and morphine consumption after mastectomy. Anesthesiology 2002;97:560-4.

26. Yoon KJ, Kim CS, Ryu KH, et al. Analgesic effects of gabapentin on post-hysterectomy pain. Korean J Anesthesiol 2001;41:S13-8.
27. Fassoulaki A, Patris K, Sarantopoulos C, Hogan Q. The analgesic effect of gabapentin and mexiletine after breast surgery for cancer. Anesth Analg 2002;95:985-91.

28. Pandey CK, Sahay S, Gupta D, et al. Preemptive gabapentin decreases postoperative pain after lumbar discectomy. Can J Anaesth 2004;51:986-9.

29. Rorarius MG, Mennander S, Suominen P, et al. Gabapentin for the prevention of postoperative pain after vaginal hysterectomy. Pain 2004;110:175-81.

30. Turan A, Memis D, Karamanlioglu B, Yagiz R, Pamukcu Z, Yavuz E. The analgesic effects of gabapentin in monitored anesthesia care for ear-nose-throat surgery. Anesth Analg. 2004;99:375-8.

31. Turan A, Karamanlioglu B, Memis D, Usar P, Pamukcu Z, Ture M. The analgesic effects of gabapentin after total abdominal hysterectomy. Anesth Anal 2004;98:1370-3.

32. Turan A, Karamanlioglu B, Memis D, et al. Analgesic effects of gabapentin after spinal surgery. Anesthesiology 2004;100:935-8.

33. Pandey CK, Priye S, Singh S, Singh U, Singh RB, Singh PK. Preemptive use of gabapentin significantly decreases postoperative pain and rescue analgesic requirements in laparoscopic cholecystectomy. Can J Anaesth 2004; 51:358-63.

34. Dierking G, Duedahl TH, Rasmussen ML, et al. Effects of gabapentin on postoperative morphine consumption and pain after abdominal hysterectomy: A randomized, double-blind trial. Acta Anaesthesiol Scand 2004;48:322-7.

35. Gilron I, Orr E, Tu D, O’Neill JP, Zamora JE, Bell AC. A placebocontrolled randomized clinical trial of perioperative administration of gabapentin, rofecoxib and their combination for spontaneous and movement-evoked pain after abdominal hysterectomy. Pain 2005;113:191-200.

36. Pandey CK, Singhal V, Kumar M, et al. Gabapentin provides effective postoperative analgesia whether administered preemptively or post-incision. Can J Anesth 2005;52:827-31.

37. Radhakrishnan M, Bithal PK, Chaturvedi A. Effect of preemptive gabapentin on postoperative pain relief and morphine consumption following lumbar laminectomy and discectomy: A randomized, double-blinded, placebo-controlled study. J Neurosurg Anesthesiol 2005;17:125-8.

38. Menigaux C, Adam F, Guignard B, Sessler DI, Chauvin M. Preoperative gabapentin decreases anxiety and improves early functional recovery from knee surgery. Anesth Analg 2005;100:1394-9.

39. Pandey CK, Navkar DV, Giri PJ, et al. Evaluation of the optimal preemptive dose of gabapentin for postoperative pain relief after lumbar diskectomy: A randomized, double-blind, placebocontrolled study. J Neurosurg Anesthesiol 2005;17:65-8.

40. Tuncer S, Bariskaner H, Reisli R, Sarkilar G, Çicekci F, Otelcioglu S. Effect of gabapentin on postoperative pain: A randomized, placebocontrolled clinical study. The Pain Clinic 2005;17:95-9.

41. Turan A, White PF, Karamanlioglu B, et al. Gabapentin: An alternative to the cyclooxygenase- 2 inhibitors for perioperative pain management. Anesth Analg 2006;102:175-81.

42. Turan A, Kaya G, Karamanlioglu B, Pamukçu Z, Apfel CC. Effect of oral gabapentin on postoperative epidural analgesia. Br J Anaesth 2006;96:242-6.

43. Rose MA, Kam PC. Gabapentin: Pharmacology and its use in pain management. Anaesthesia 2002;57:451-62.

44. Gilron I. Is gabapentin a "Broad-spectrum" analgesic? Anesthesiology 2002;97:537-9.

45. Seib RK, Paul JE. Preoperative gabapentin for postoperative analgesia: A meta-analysis. Can J Anesth 2006;53;461-9.

46. Hurley RW, Cohen SP, Williams KA, Rowlingson AJ, Wu CL. The analgesic effects of perioperative gabapentin on postoperative pain: A meta-analysis. Reg Anesth Pain Med 2006;31:237-47.

47. KY Ho, Gan TJ, Habib AS. Gabapentin and postoperative pain A systematic review of randomized controlled trials. Pain 2006;126:91-101.

48. Woolf CJ, Chong MS. Preemptive analgesia-treating postoperative pain by preventing the establishment of central sensitization. Anesth Analg 1993;77:362-79.

49. Woolf CJ, Salter MW. Neuronal plasticity: Increasing the gain in pain. Science 2000;288:1765-9.

50. Scholz J, Woolf CJ. Can we conquer pain? Nat Neurosci 2002;5:1062-7.

51. Macrae WA. Chronic pain after surgery. Br J Anaesth 2001;87:88-98. 
52. Perkins FM, Kehlet H. Chronic pain as an outcome of surgery. A review of predictive factors. Anesthesiology 2000;93:1123-33.

53. Maneuf YP, Gonzalez MI, Sutton KS, Chung FZ, Pinnock RD, Lee K. Cellular and molecular action of the putative GABA-mimetic, gabapentin. Cell Mol Life Sci 2003;60:742-50.

54. Taylor CP, Gee NS, Su TZ, et al. A summary of mechanistic hypotheses of gabapentin pharmacology. Epilepsy Res 1998;29:233-49.

55. Martin DJ, McClelland D, Herd MB, et al. Gabapentin-mediated inhibition of voltage-activated $\mathrm{Ca}^{2+}$ channel currents in cultured sensory neurons is dependent on culture conditions and channel subunit expression. Neuropharmacology 2002;42:353-66.

56. Cepeda MS, Africano JM, Polo R, Alcala R, Carr DB. What decline in pain intensity is meaningful to patients with acute pain? Pain 2003;105:151-7.

57. Edwards JE, McQuay HJ, Moore RA, Collins SL. Reporting of adverse effects in clinical trials should be improved: Lessons from acute postoperative pain. J Pain Symptom Manage 1999;18:427-37.

58. Dworkin RH, Backonja M, Rowbotham MC, et al. Advances in neuropathic pain. Diagnosis, mechanisms, and treatment recommendations. Arch Neurol 2003;60:1524-34.

59. Apfelbaum JL, Gan TJ, Zhao S, Hanna DB, Chen C. Reliability and validity of the perioperative opioid-related symptom distress scale. Anesth Analg 2004;99:699-709.
60. Kehlet H. Procedure-specific postoperative pain management. Anesthesiology Clin North Am 2005;23:203-10.

61. Gray A, Kehlet H, Bonnet F, Rawal N. Predicting postoperative analgesia outcomes: NNT league tables or procedure-specific evidence? Br J Anaesth 2005;94:710-4

62. Dirks J, Petersen KL, Rowbotham MC, Dahl JB. Gabapentin suppresses cutaneous hyperalgesia following heat/capsaicin sensitization. Anesthesiology 2002;97:102-7.

63. Eckhardt K, Ammon S, Hofmann U, Riebe A, Gugeler N, Mikus G. Gabapentin enhances the analgesic effect of morphine in healthy volunteers. Anesth Analg 2000;91:185-91.

64. Werner MU, Perkins FM, Holte K, Pedersen JL, Kehlet H. Effects of gabapentin in acute inflammatory pain in humans. Reg Anesth Pain Med 2001;26:322-8.

65. Letterman L, Markowitz JS. Gabapentin: A review of published experience in the treatment of bipolar disorder and other psychiatric conditions. Pharmacotherapy 1999;19:565-72.

66. Ehrenberg B. Importance of sleep restoration in co-morbid disease: Effect of anticonvulsants. Neurology 2000;54:S33-7.

67. De Kock M, Lavand'homme P, Waterloos H. 'Balanced analgesia' in the perioperative period: Is there a place for ketamine? Pain 2001;92:373-80.

68. Jadad AR, Moore RA, Carroll D, et al. Assessing the quality of reports of randomized clinical trials: Is blinding necessary? Control Clin Trials 1996;17:1-12. 


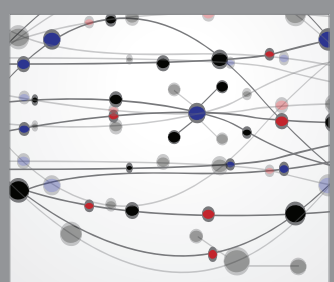

The Scientific World Journal
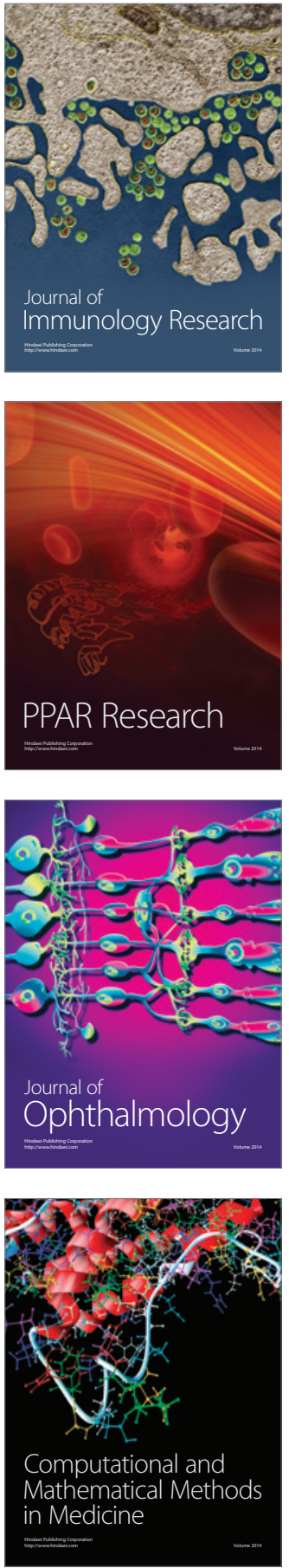

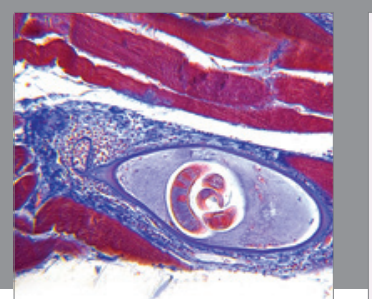

Gastroenterology Research and Practice

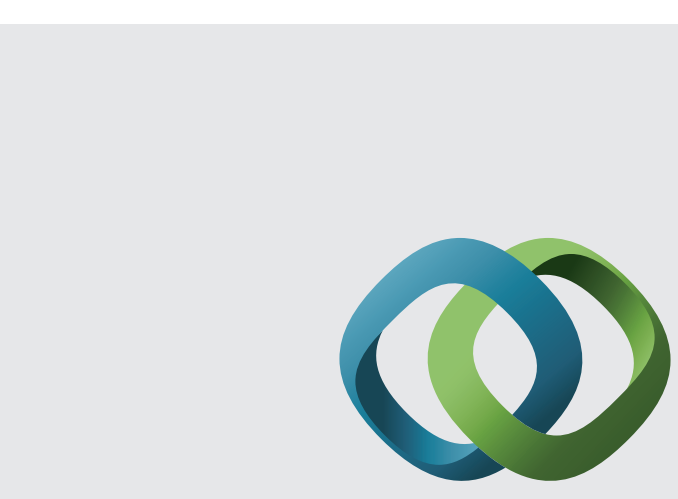

\section{Hindawi}

Submit your manuscripts at

http://www.hindawi.com
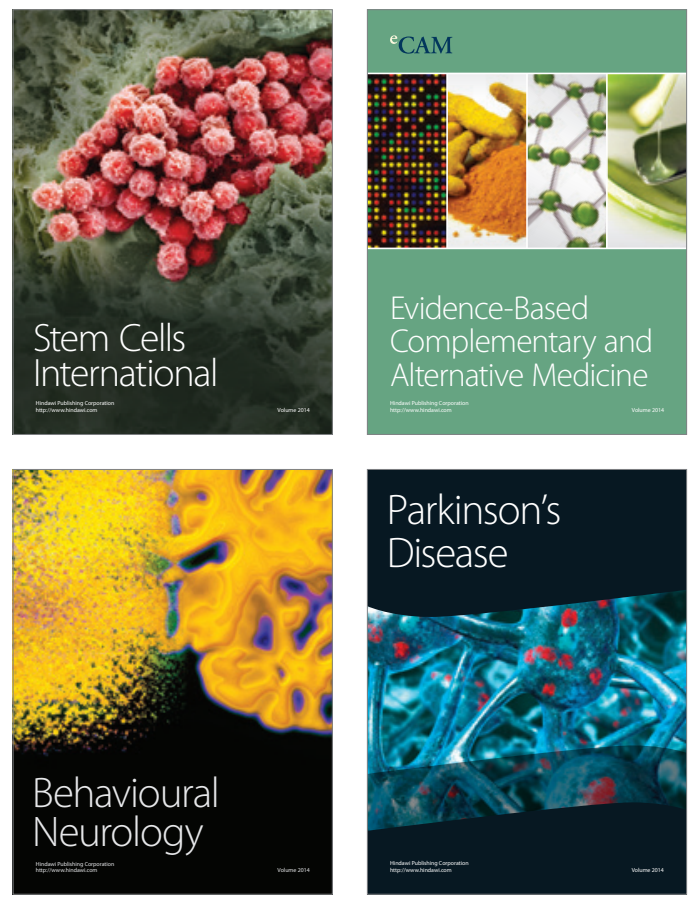
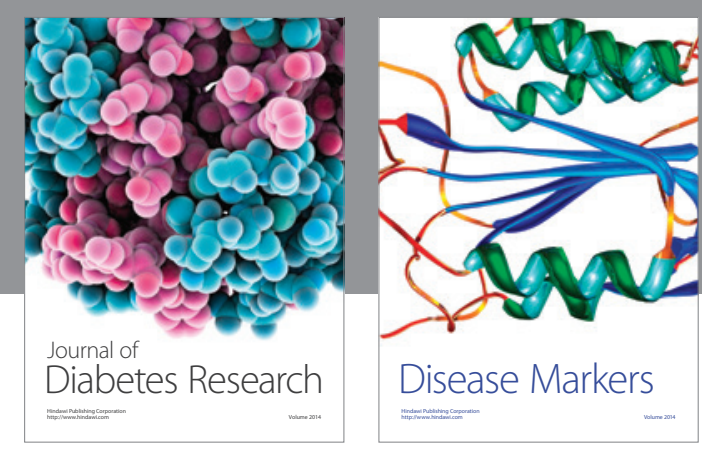

Disease Markers
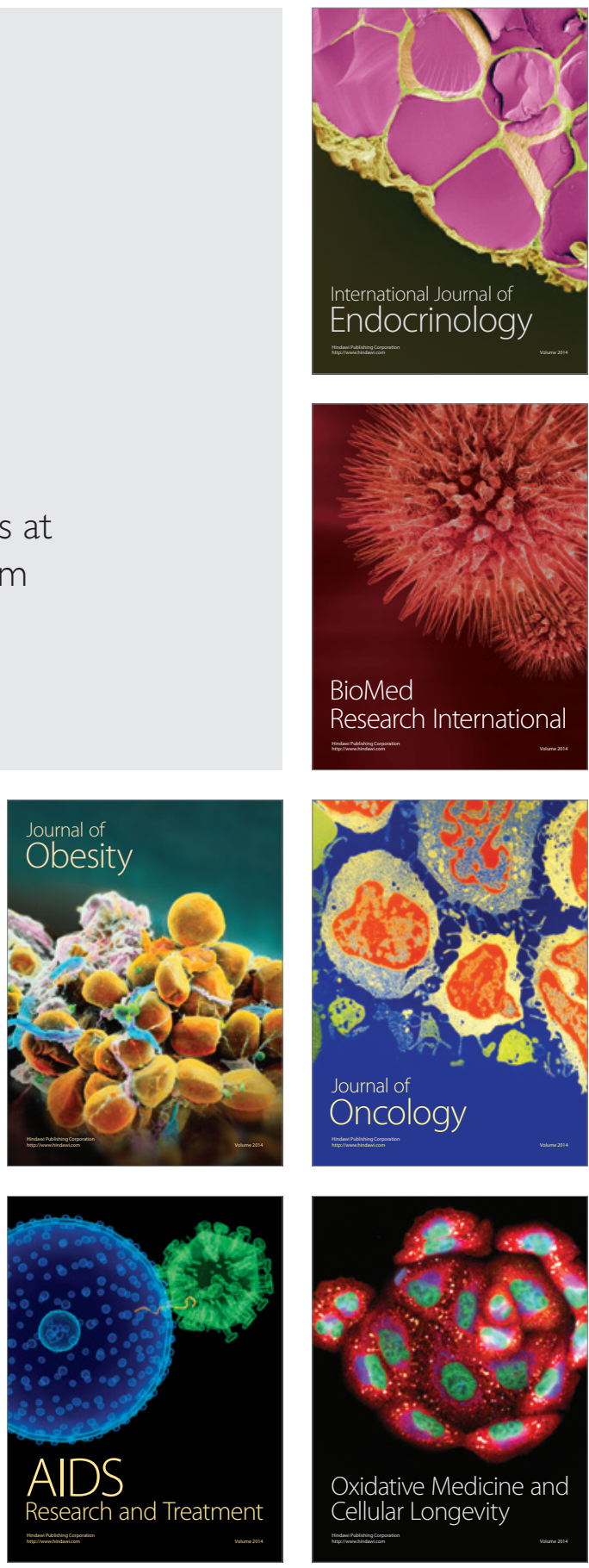